\title{
Aspectos morfológicos, morfométricos e ultraestruturais do baço de ratos após o clampeamento total do pedículo hepático
}

\author{
[Morphologic, morphometric, and ultrastructural aspects of the spleen of rats after \\ hepatic pedicle total clamping] \\ S.H. Freitas ${ }^{1}$, J. Evêncio Neto ${ }^{2}$, R.G.S. Dória ${ }^{1}$, F.S. Mendonça ${ }^{1}$, M.J. Simões ${ }^{3}$, \\ L.M. Camargo ${ }^{1}$, A.A. Sebe \\ ${ }^{1}$ Faculdade de Medicina Veterinária - UNIC - Cuiabá, MT \\ ${ }^{2}$ Universidade Federal Rural de Pernambuco - Recife, PE \\ ${ }^{3}$ Universidade de Federal de São Paulo - São Paulo, SP \\ ${ }^{4}$ Faculdade de Medicina - UNIC - Cuiabá, MT
}

\begin{abstract}
RESUMO
Avaliaram-se as alterações morfológicas, morfométricas e ultraestruturais que ocorreram no baço devido à isquemia produzida pelo clampeamento total do pedículo hepático. Para tanto, foram utilizados 40 ratos machos, distribuídos em quatro grupos de 10 animais. O grupo-controle (C) não foi submetido à isquemia, e os grupos tratados $\left(E_{1}, E_{2}\right.$ e $\left.E_{3}\right)$ foram submetidos ao clampeamento por 10, 20 e 30 minutos, respectivamente. Fragmentos do baço foram retirados e analisados histologicamente pela microscopia de luz (hematoxilina-eosina, ferrocianeto-férrico) e pela microscopia eletrônica de transmissão. Os resultados demonstraram que 10 minutos de clampeamento do pedículo hepático são suficientes para apresentar sinais de congestão esplênica e 20 e 30 minutos promovem intensa digestão de hemácias pelos macrófagos, com presença de grânulos de ferro (hemossiderina) no parênquima esplênico.
\end{abstract}

Palavras-chave: rato, baço, clampeamento, pedículo hepático, hemossiderina

\begin{abstract}
The macro and microscopic alterations that occurred in the spleen during an ischemia produced by the hepatic pedicle total clamping were studied. Forty male rats were distributed in four groups of 10 animals each. The control group $(C)$ was not submitted to ischemia and the treated groups $\left(E_{1}, E_{2}\right.$, and $\left.E_{3}\right)$ were submitted to the clamping during 10, 20, and 30 minutes, respectively. Spleen fragments were collected and histologically analyzed by the light microscopy (eosin-hematoxilin and ferric ferrocyanide) and by the transmission electron microscopy. The results showed that 10 minutes of hepatic pedicle total clamping was enough produce signs of splenic congestion and 20 and 30 minutes promoted intense red bood cels digestion by the macrophages with the presence of iron granules (hemosiderin) in the splenic parenchyma.
\end{abstract}

Keyword: rat, spleen, clamping, hepatic pedicle, hemossiderin

\section{INTRODUÇÃO}

Nas lesões sangrantes do fígado, o bloqueio dos vasos é necessário para facilitar as manobras cirúrgicas (Silva Jr. et al., 2002; Araújo Jr. et al., 2005). Pringle (1908) realizou clampeamento total do hilo hepático para conter hemorragias hepáticas, e Sebe (1999), Freitas et al. (1999, 2000) e Camargo et al. (2003) demonstraram que o clampeamento total do pedículo hepático, utilizado para conter a hemorragia nos procedimentos cirúrgicos do fígado, resulta em congestão esplâncnica e, consequentemente, perfusão sanguínea deficiente de órgãos como estômago, intestino delgado e parte anterior do intestino grosso, pâncreas e baço. Barbarino et al. (1978) utilizaram apenas o clampeamento isolado da veia porta com a finalidade de

Recebido em 11 de setembro de 2008

Aceito em 30 de agosto de 2009

E-mail: shfreitas@terra.com.br 
diminuir o afluxo de sangue para o fígado e a congestão esplâncnica e, mesmo assim, observaram esplenomegalia, com aumento da polpa vermelha e diminuição do número de nódulos linfáticos, que se apresentaram aumentados de tamanho.

O baço atua como importante reservatório de sangue, podendo, quando solicitado e sob ação das catecolaminas, elevar o hematócrito em até $10 \%$ do seu valor normal (Lipowitz e Blue, 1998). Nos recém-nascidos, ele tem função hematopoiética e, quando necessário, também pode produzir hemácias nos adultos (Lipowitz e Blue, 1998). Além disso, está envolvido na produção de linfócitos $\mathrm{T}$ e $\mathrm{B}$ e de anticorpos (Lipowitz e Blue, 1998; Richard e Sherind, 1998).

O baço, devido à sua malha estrutural tridimensional, realiza o monitoramento de células sanguíneas viáveis, favorecendo a fagocitose dos leucócitos, plaquetas e eritrócitos senis pelos macrófagos (Zhang, 2001). Assim, hemácias velhas ou parasitadas, por perderem a sua flexibilidade e por não conseguirem penetrar nos sinusoides, são fagocitadas e destruídas pelos macrófagos, em um processo denominado hemocaterese. Esses macrófagos são células muito ativas, que apresentam superfície irregular, com inúmeras saliências e reentrâncias, e citoplasma contendo numerosos lisossomos que depositam suas enzimas nos vacúolos que contêm material fagocitado, formando os fagossomos, onde vai ser realizada a digestão do material fagocitado (Gartner e Hiatt, 2007; Junqueira e Carneiro, 2008). A hemoglobina, resultante da digestão de hemácias, desdobra-se nas porções heme e globina. A fração globina é quebrada em seus constituintes de aminoácidos que vão para a circulação sanguínea. As moléculas de ferro, da fração heme, no interior dos macrófagos, se agrupam formando um pigmento denominado de hemossiderina, que são levados à medula óssea pela transferrina, onde são utilizadas para formação de novas hemácias (Swenson e Reece, 1996; Couto e Hammer, 1997; Gartner e Hiatt, 2007, Alencar et al., 2002).

O objetivo deste trabalho foi avaliar as alterações morfológicas, morfométricas e ultra-estruturais do baço durante o clampeamento total do pedículo hepático (manobra de Pringle modificada).

\section{MATERIAL E MÉTODOS}

Foram utilizados 40 ratos Wistar, machos, com 90 dias de idade e pesos variando de 232 a 359 gramas. Os animais foram alojados em gaiolas à temperatura ambiente de $22^{\circ} \mathrm{C}$, umidade relativa de $65 \%$ e luminosidade controlada artificialmente com lâmpadas fluorescentes, com 12 horas de luz e 12 horas de escuro.

Após jejum alimentar de duas horas, os animais foram distribuídos aleatoriamente em quatro grupos de 10 animais: grupo-controle (C), formado por animais submetidos à anestesia dissociativa $\left(25 \mathrm{mg} / \mathrm{kg}\right.$ de xilazina ${ }^{1}$ e $50 \mathrm{mg} / \mathrm{kg}$ de cetamina $^{2}$, intramuscular), celiotomia e retirada do baço após 30 minutos, sem clampeamento do pedículo hepático; e grupos tratados $\mathrm{E}_{1}, \mathrm{E}_{2}$ e $\mathrm{E}_{3}$, formados por animais submetidos, respectivamente, à anestesia, celiotomia e retirada do baço após 10, 20 e 30 minutos de clampeamento total do pedículo hepático, abrangendo a artéria hepática, veia porta e ducto colédoco - manobra de Pringle, modificada (Pringle, 1908).

Após remoção do baço, os animais foram sacrificados seguindo o mesmo padrão anterior de anestesia e, na sequência, usou-se cloreto de potássio a $10 \%{ }^{3}$.

Para as análises histológicas e morfométricas, fragmentos do terço médio do baço foram fixados em solução de formaldeído $10 \%$ por 24 horas. Após fixação, foram submetidos às técnicas rotineiras para microscopia de luz, sendo infiltrados com parafina. Os cortes foram corados com hematoxilina-eosina (HE) e analisados em microscópio de luz ${ }^{4}$, com objetivas que variavam de 4 a $100 \mathrm{X}$ e ocular de $10 \mathrm{X}$.

Para análise do ferrocianeto férrico, alguns cortes histológicos foram submetidos à metodologia citoquímica para identificação dos íons de ferro,

${ }^{1}$ Virbaxil 2\% - Virbac do Brasil Indústria e Comércia Ltda, São Paulo, Brasil.

${ }^{2}$ Vetanarcol - Koning do Brasil Ltda, Florianópolis, Brasil.

${ }^{3}$ Cloreto de potásio 10\% - Aster Produtos Médicos Ltda, Sorocaba, Brasil.

${ }^{4}$ Axiolab 2.0 - Carl Zeiss, Sofia, Bulgária. 
pelo método de Perls (ferrocianeto-férrico), que é a reação dos íons ferrocianeto do corante (ferrrocianeto de potássio) com os íons férricos no interior da célula, resultando em um produto azul-esverdeado, denominado ferrocianeto férrico (Cançado, 2007; Cançado et al., 2007). Os estudos morfométricos foram realizados sobre as imagens dos preparados citoquímicos, obtidas por um sistema de captura de imagens ${ }^{5}$ e analisadas com o auxílio de um sistema computacional de análise de imagens (softwares IMAGELAB 2000). Foram capturados 10 campos da região da polpa vermelha do baço em cada animal, na região imediatamente ao redor da polpa branca. Em cada campo, foi obtida a área contendo grânulos de ferro (valor percentual), sendo, ao final, obtido um valor médio para cada animal.

Para o estudo ultraestrutural, fragmentos do terço médio do baço foram imediatamente imersos em solução de glutaraldeído 4,0\% (0,32 osmolar), em tampão cacodilato de sódio $0,1 \mathrm{M}$, em pH 7,2, à temperatura de $4^{\circ} \mathrm{C}$, por quatro horas. Eles foram processados pela técnica de rotina para microscopia eletrônica de transmissão. Os cortes ultrafinos foram contrastados com citrato de chumbo e acetato de uranila e observados em microscópio eletrônico de transmissão ${ }^{6}$. Nas eletromicrografias obtidas, foi observada a morfologia geral da polpa vermelha, em especial os macrófagos.

Os dados da porcentagem dos pigmentos férricos de hemossiderina foram submetidos, inicialmente, à análise de variância, complementados pelos testes KolmogorovSmirnov, Levene e Welch e Brown-Forsythe (software - SPSS 15.0). O nível de significância máximo adotado foi $\mathrm{P}<0,05$.

\section{RESULTADOS}

Macroscopicamente, após o período de clampeamento do hilo hepático, observou-se que o baço dos grupos tratados $\left(E_{1}, E_{2} \quad e_{3}\right)$ mostrava-se de vermelho escuro a azulado, semelhantes ao do grupo-controle (C).

No grupo C, foi observado baço circundado por uma cápsula de tecido fibromuscular que emitia

\footnotetext{
${ }^{5}$ Axio Vision - Carl Zeiss, Sofia, Bulgária.

${ }^{6}$ Modelo EM 900 - Carl Zeiss, Sofia, Bulgária.
}

trabéculas para o seu interior. No interior do órgão, notou-se, no parênquima, acúmulo de linfócitos que formavam os nódulos linfáticos e bainhas linfocitárias periarteriolares com arteríola central na polpa branca. Ao redor dos nódulos linfáticos, observaram-se vários capilares contendo hemácias no seu interior (polpa vermelha), sendo os capilares rodeados por macrófagos. Alguns macrófagos apresentaram pequena quantidade de grânulos de hemossiderina no seu interior e, após a reação ao ferrocianeto de potássio (reação de Perls), observou-se pequena quantidade de pigmentos férricos, azulados (Fig. 1C e 2C; Tab. 1).

No grupo $E_{1}$, a arquitetura do baço foi semelhante à do grupo C. Entretanto, observouse ligeira vasodilatação nos seios esplênicos presentes na polpa vermelha e maior quantidade de grânulos azulados de hemossiderina que no grupo $\mathrm{C}$ (Fig. $1 \mathrm{E}_{1}$ e $2 \mathrm{E}_{1}$; Tab. 1).

No grupo $E_{2}$, notou-se que o baço também apresentava a arquitetura histológica similar à observada no grupo C. No entanto, percebeu-se diminuição da polpa branca, tanto da porção cordonal quanto da nodular. A polpa vermelha mostrou-se bem evidente, com intensa dilatação dos capilares sinusoides e concentração acentuada de grânulos de hemossiderina (Fig. $1 \mathrm{E}_{2}$ e $2 \mathrm{E}_{2}$; Tab. 1).

No grupo $E_{3}$, foi observado acentuado aumento da polpa vermelha devido à acentuada dilatação dos vasos sanguíneos e elevada concentração de grânulos de hemossiderina (Fig. $1 \mathrm{E}_{3}$ e $2 \mathrm{E}_{3}$; Tab. 1).

Os dados relativos à análise morfométrica da área contendo grânulos de hemossiderina são apresentados na Tab. 1.

No baço dos animais controle foram observados macrófagos em contato com eritrócitos, sendo que alguns deles apresentavam grânulos citoplasmáticos eletrondensos (Fig. 3C). No dos animais dos grupos $E_{1}, E_{2}$ e $E_{3}$, verificaram-se, no interior dos macrófagos, grânulos eletrondensos, que se acentuaram com o aumento do tempo de clampeamento (Fig. $3 \mathrm{E}_{1}, \mathrm{E}_{2}$ e $\mathrm{E}_{3}$ ). Em alguns macrófagos, notou-se que os grânulos eletrondensos eram constituídos por restos de hemácias ou outras células fagocitadas (Fig. 3 $\mathrm{E}_{1}, \mathrm{E}_{2}$ e $\mathrm{E}_{3}$ ). 

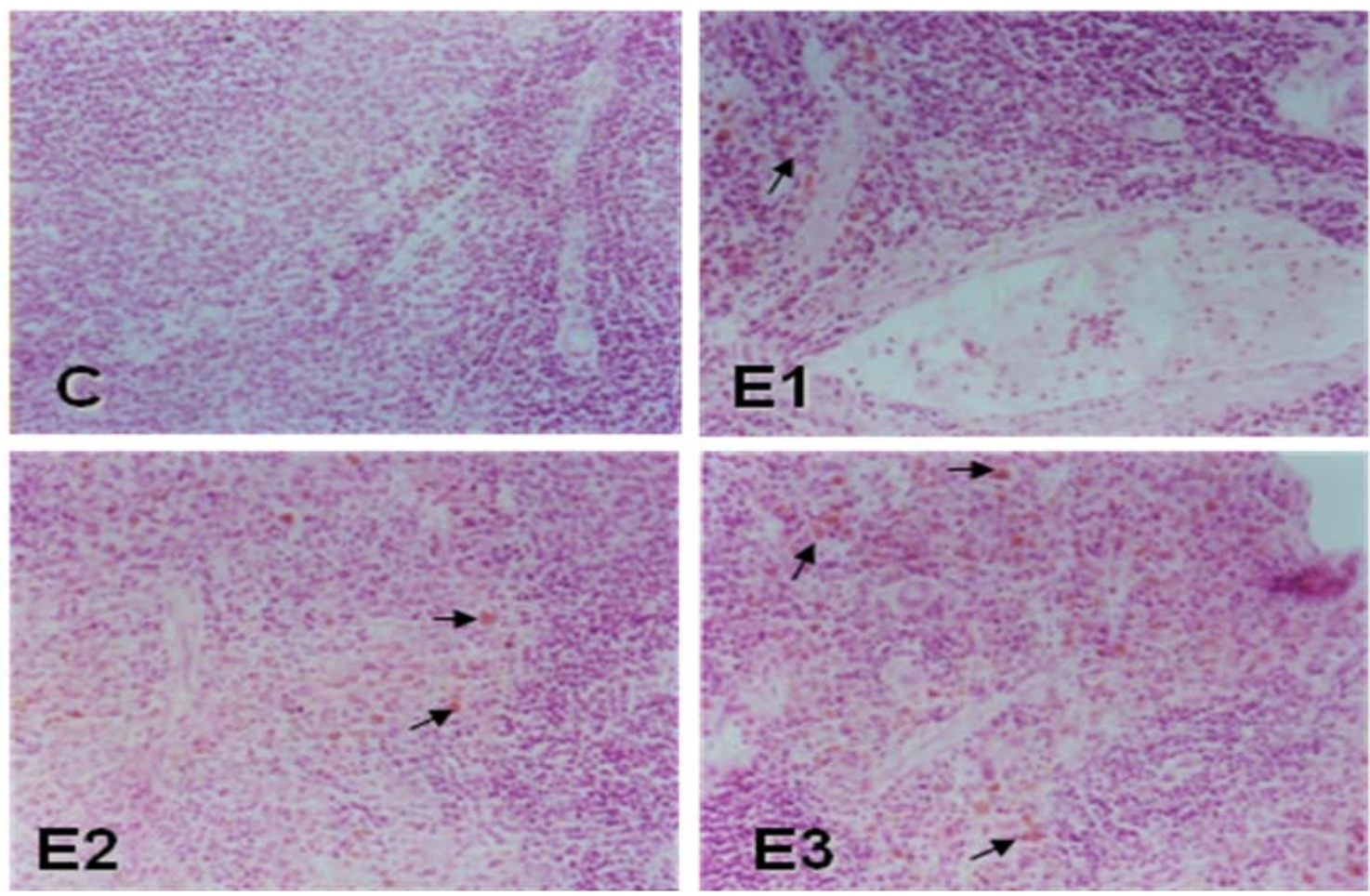

Figura 1. Fotomicrografias mostrando cortes histológicos do baço de ratos pertencentes aos vários grupos de estudo. Notar em C (grupo-controle) polpa vermelha com poucos grânulos de hemossiderina que, no entanto, estão aumentados (setas) nos grupos submetidos ao clampeamento total do pedículo hepático por 10 minutos $\left(\mathrm{E}_{1}\right), 20$ minutos $\left(\mathrm{E}_{2}\right)$ ou 30 minutos $\left(\mathrm{E}_{3}\right)$. HE $10 \mathrm{X}$.
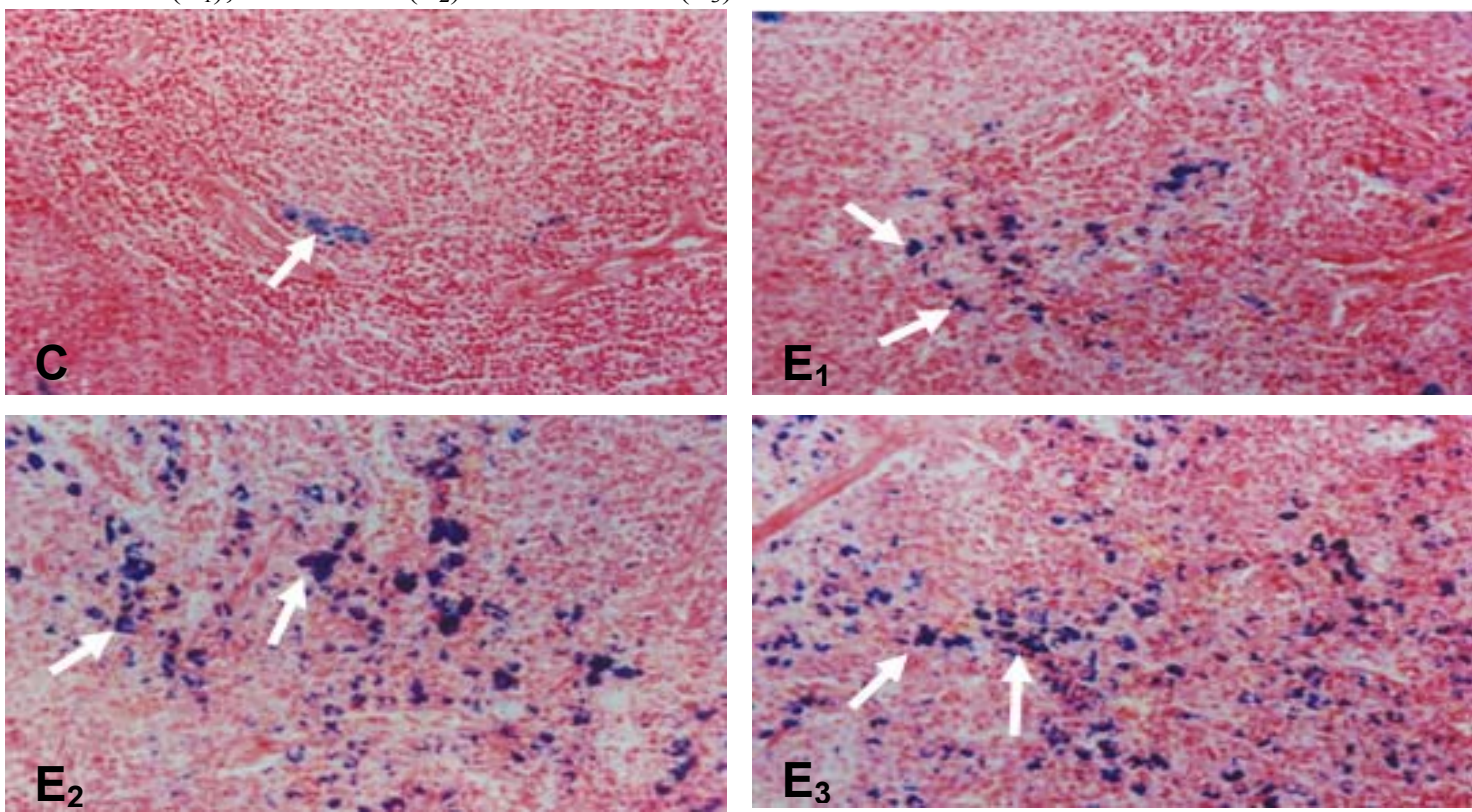

Figura 2. Fotomicrografias mostrando cortes histológicos do baço de ratos pertencentes aos vários grupos de estudo. Notar em C (grupo-controle) pouca reatividade para grânulos de hemossiderina, que se acham aumentados, de forma acentuada e progressiva (setas), nos grupos submetidos ao clampeamento total do pedículo hepático por 10 minutos $\left(\mathrm{E}_{1}\right), 20$ minutos $\left(\mathrm{E}_{2}\right)$ ou 30 minutos $\left(\mathrm{E}_{3}\right)$. Reação de Perls (ferrocianetoférrico) $10 \mathrm{X}$. 


\section{Freitas et al.}

Tabela 1. Porcentagem de pigmento de hemossiderina (média \pm desvio-padrão) obtida na polpa vermelha do baço de ratos pertencentes aos grupos-controle ou submetidos ao clampeamento total do pedículo hepático por 10 minutos $\left(\mathrm{E}_{1}\right), 20$ minutos $\left(\mathrm{E}_{2}\right)$ ou 30 minutos $\left(\mathrm{E}_{3}\right)$

\begin{tabular}{ccccc}
\hline Grupo & Controle (\%) & E1 (\%) & E2 (\%) & E3 (\%) \\
\hline $\begin{array}{c}\text { Média } \pm \\
\text { Desvio-padrão }\end{array}$ & $1,45 \pm 0,28 \mathrm{~A}$ & $1,95 \pm 0,44 \mathrm{~B}$ & $4,92 \pm 1,29 \mathrm{C}$ & $17,05 \pm 2,15 \mathrm{D}$ \\
\hline
\end{tabular}

Médias seguidas de letras distintas na linha diferem entre si $(\mathrm{P}<0,05)$.
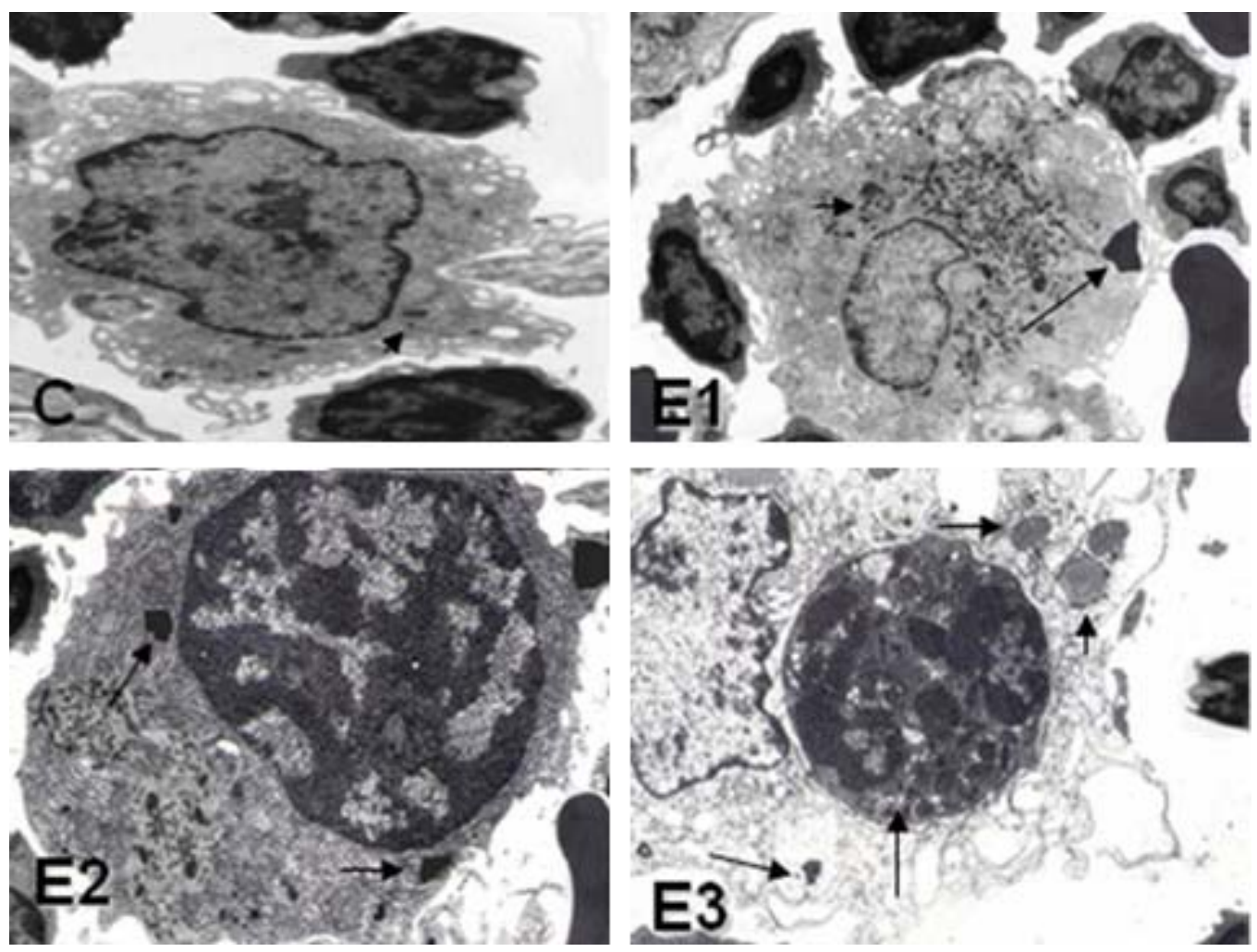

Figura 3. Eletromicrografias mostrando macrófagos presentes nos cordões de Billroth dos ratos pertencentes ao grupo-controle $(\mathrm{C})$ e aos grupos submetidos ao clampeamento total do pedículo hepático por 10 minutos $\left(E_{1}\right), 20$ minutos $\left(E_{2}\right)$ ou 30 minutos $\left(E_{3}\right)$. Notar em $C$ (grupo-controle) poucos grânulos eletrondensos (seta), que aumentam em números (setas) com o decorrer do tempo de clampeamento hepático. $8200 \mathrm{X}$.

\section{DISCUSSÃO}

A torção esplênica primária ou secundária, decorrente da dilatação e vólvulo-gástrico, em pequenos animais, inicialmente promove a oclusão das veias de paredes delgadas, mas não das artérias correspondentes, resultando em congestão, isquemia e, posteriormente, necrose do parênquima esplênico. A patogênese da torção ainda não está bem esclarecida, porém o grau de lesão esplênica depende do comprometimento dos vasos e do tempo de privação sanguínea para esse órgão (Pope e
Rochat, 1996). Neste estudo, a congestão esplênica observada após clampeamento total do pedículo hepático não promoveu necrose, pois a obstrução vascular comprometeu apenas a circulação venosa, mantendo-se intacta a circulação arterial. Provavelmente, o tempo de clampeamento não foi suficiente para causar necrose desse órgão, embora tenha promovido congestão esplâncnica, que resultou na congestão esplênica. Barbarino et al. (1978) já haviam utilizado apenas a ligação da veia porta e observaram, em relação ao baço, esplenomegalia, aumento da proporção de polpa vermelha e 
diminuição do número de folículos linfoides, como pôde, também, ser observado neste trabalho. Da mesma forma, Sebe et al. (2000) e Camargo et al. (2003) observaram congestão esplâncnica, com mudança de coloração dos órgãos drenados pelo sistema porta.

De acordo com a literatura consultada, os tempos de isquemia hepática variam de 30 até 100 minutos (Asakava et al., 1989; Isozaki et al., 1995), sendo os maiores períodos relacionados com trabalhos que envolvem isquemia hepática parcial ou total com derivações vasculares, e os menores, com trabalhos que envolvem isquemia total, sem derivações vasculares, como descrito por Sébe (1999) e reproduzido neste estudo.

No modelo experimental realizado por Sébe (1999), Freitas et al. $(1999,2000)$ e Camargo et al. (2003), utilizando a manobra de Pringle modificada por 10, 20 e 30 minutos, observaramse isquemia hepática, intestinal e congestão esplênica, decorrentes da congestão esplâncnica. A isquemia hepática total em diferentes tempos acarreta congestão esplâncnica e, consequentemente, congestão esplênica, que é caracterizada pela diminuição da polpa branca (nódulos linfáticos) e pelo aumento da polpa vermelha, sendo essa mais intensa aos 30 minutos, conforme relatado por Freitas et al. (2006) e confirmada neste estudo.

A hemocaterese fisiológica de eritrócitos envelhecidos, lesionados ou enfermos pelos macrófagos libera grande concentração de ferro reutilizável, que é armazenado pelo baço e parte direcionado à medula óssea para ser utilizado na produção de novas hemácias (Pope e Rochat, 1996; Alencar et al., 2002).

O clampeamento do hilo hepático pode reduzir a concentração de energia e intensificar a acidose láctica esplênica, podendo causar danos às membranas dos eritrócitos e alteração de sua plasticidade, aumentando sua fagocitose pelos macrófagos, resultando em maior produção de pigmentos férricos de hemossiderina. Essas alterações ocorrem devido ao fato de a concentração de glicose e colesterol nos seios venosos esplênicos ser menor se comparada ao restante do sistema circulatório, que, juntamente com a produção de ácido láctico por meio do metabolismo das hemácias, resulta em um ambiente tolerado apenas por hemácias jovens e saudáveis, levando ao descarte das hemácias velhas ou enfermas (Pope e Rochat, 1996).

O aumento da pressão sanguínea e da temperatura esplênica podem, também, lesionar os eritrócitos e intensificar a eritrofagocitose pelos macrófagos (Pope e Rochat, 1996). Nesse experimento, notou-se comprometimento da drenagem venosa esplênica realizada pelo sistema porta durante o clampeamento do pedículo hepático, caracterizado pela congestão esplênica que, possivelmente, acarretou aumento da pressão sanguínea intraesplênica. Dessa forma, o acúmulo progressivo de pigmentos férricos de hemossiderina, observado no interior dos macrófagos, caracteriza a eritrofagocitose decorrente do aumento da pressão sanguínea no parênquima e seios venosos esplênicos.

Os oxirradicais livres (ânions hiperóxidos, radicais hidroxila e peróxido de hidrogênio) são moléculas altamente reativas e capazes de causar lesões celulares e no DNA. O peróxido de hidrogênio não é um radical livre, porém, com a produção acelerada e em presença de catalizadores metálicos como o ferro, por meio da reação de Haber-Weiss, forma radicais hidroxila reativos $\left(\mathrm{OH}^{-}\right)$(Flaherty e Weisfeldt, 1988; Ambrósio et al., 2000; Alencar et al., 2002; Valcarenghi, 2006; Gonçalves et al., 2007). Neste experimento, notou-se aumento considerado de pigmentos férricos de hemossiderina, proporcionalmente ao tempo de clampeamento. É possível que os pigmentos férricos contidos nos macrófagos, após $\mathrm{o}$ desclampeamento do hilo hepático, possam adentrar a circulação e aumentar a produção de radicais livres, causando lesões às membranas celulares e, dependendo do grau destas lesões, levar a óbito o paciente no pós-operatório.

\section{CONCLUSÕES}

Dez minutos de clampeamento total do pedículo hepático são suficientes para promover sinais de congestão esplênica, enquanto 20 e 30 minutos de clampeamento resultam em diminuição da polpa branca, dilatação dos capilares sinusoides e intensa hemocaterese pelos macrófagos, evidenciada pela presença de grânulos de hemossiderina no parênquima esplênico. 


\section{REFERÊNCIAS BIBLIOGRÁFICAS}

ALENCAR, N.X.; KOHAYAGAWA, A.; CAMPOS, K.C.H. Metabolismo do ferro nos animais domésticos: revisão. Rev. Educ. Contin., v.5, p.196-205, 2002.

AMBRÓSIO, A.M.; FANTONI, D.T.; MIGLIAT, E.R. Síndrome de isquemia e reperfusão em cães: revisão de literatura. Clin. Vet., n.24, p.34-38, 2000.

ARAÚJO Jr., F.A.; BRAZ, M.N.; ROCHA NETO, O.G. et al. Efeito do óleo de copaíba nas aminotransferases de ratos submetidos à isquemia e reperfusão hepática com e sem précondicionamento isquêmico. Acta Cir. Bras., v.20, p.93-99, 2005.

ASAKAVA, H.; JEPPSON, B.; MACK, P. et al. Acute ischemic liver failure in the rat: a reproducible model not requirint portal decompression. Eur. Surg. Res., v.21, p.42-8, 1989.

BARBARINO, F.; NEUMANN, E.; TAMAS, S. et al. Morphologic, histoenzymatic and radioisotopic changes in the liver after portal veins ligation. Med. Intern., v.16, p.375-381, 1978 .

CAMARGO, L.M.; EVÊNCIO NETO, J.; FREITAS, S.H. et al. Aspectos ultra-estruturais das vilosidades intestinais após o clampeamento do pedículo hepático de ratos. Acta Cir. Bras., v.18, p.509-513, 2003.

CANÇADO, R.D. Sobrecarga e quelação de ferro na anemia falciforme. Rev. Bras. Hematol. Hemoter., v. 29, 316-326, 2007.

CANÇADO, R.D.; GUGLIELMI, A.C.O.; VERGUEIRO, C. S. V. et al. Estudo das mutações C282Y, H63D e S65C do gene HFE em doentes brasileiros com sobrecarga de ferro. Rev. Bras. Hematol. Hemoter., v.29, p.351-360, 2007.

COUTO, C.G.; HAMMER, A.S. Afecções dos linfonodos e baço. In: ETTINGER, S.J.; FELDMAN, E.C. Tratado de medicina interna veterinária. 4.ed. São Paulo: Manole, 1997, v.2, p.2684-2696.

FLAHERTY, J.T.; WEISFELDT, M.L. Reperfusion injury. Free Radic. Biol. Med., v.5, p.409-19, 1988.
FREITAS, S.H.; EVENCIO NETO, J.; SANTOS, M.D. et al. Avaliação qualitativa de pigmentos de hemossiderina em parênquima esplênico de ratos após o clampeamento da veia porta hepática. In: CONGRESSO BRASILEIRO DE MEDICINA VETERINÁRIA, 33., 2006, Cuiabá, MT. Anais... Cuiabá, MT: SOMATOVET, 2006, p.26. (Resumo).

FREITAS, S.H.; SEBE, A.A.; CAMARGO, L.M. et al. Alterações esplênicas em ratos após o clampeamento do pedículo hepático. Arq. Inst. Biol., v. 66, supl., p.61, 1999. (Resumo).

FREITAS, S.H.; SIMÕES, M.J.; CUBAS, J.J.M. et al. Efeito do clampeamento temporário do pedículo hepático sobre a morfologia do baço de ratos. Arq. Inst. Biol., v. 67, supl., p.56, 2000. (Resumo).

GARTNER, L.P.; HIATT, J.L. Tratado de histologia. 3.ed. Rio de Janeiro: Guanabra Koogan, 2007. p.228-233.

GONÇALVES, L.H.; VAZ, L.S.; BUZZI, M. Avaliação dos níveis de hiper-homocisteinemia, vitamina E, selênio, cobre, ceruloplasmina e ferritina em pacientes com diagnóstico de acidente vascular cerebral isquêmico. J. Bras. Patol. Med. Lab., v.43, p.9-15, 2007.

ISOZAKI, H.; OKAJIMA, K.; KOBAYASHI, M. et al. Experimental study of liver injury after partial hepatectomy with intermittent or continuous hepatic vascular oclusion. Eur. Surg. Res., v.217, p.313-322, 1995.

JUNQUEIRA, L.C.; CARNEIRO, J. Histologia básica. 11.ed. Rio de Janeiro: Guanabara Koogan, 2008. p.275-279.

LIPOWITZ, A.J.; BLUE, I. Baço. In: SLATTER, D. Manual de cirurgia de pequenos animais. 2.ed. v.1, São Paulo: Manole, 1998. p.1143-1153.

POPE, E.R; ROCHAT, M.C. Baço. In: BOJRAB, M.J. Mecanismo da molestia na cirurgia dos pequenos animais. 2.ed. São Paulo: Manole, 1996. p.722-728.

PRINGLE, J.H. Notes on the arrest of hepatic hemorhage due to trauma. Ann. Surg., v.48, p.541-549, 1908.

RICHARD, S.J.; SHERIND, R.G. Clínica de pequenos animais. São Paulo: Roca, 1998. p.206-207. 
SÉBE, A.A. Efeitos de diferentes tempos de isquemia no figado de ratos. 1999. 90f. (Tese de Doutorado) - Escola Paulista de Medicina, Universidade de São Paulo, São Paulo.

SEBE, A.A.; NIGRO, A.J.T.; GOMES, P.O. et al. Efeito do clampeamento do pedículo hepático nos intestinos. Acta Cir. Bras., v.15, p.4-8, 2000.

SILVA Jr., O.C.; CENTURION, S.; PACHECO, E.G. et al. Aspectos básicos da lesão de isquemia e reperfusão e do pré-condicionamento isquêmico. Acta Cir. Bras., v.17, supl., p.96-100, 2002.
SWENSON, M.J.; REECE, W.O. Dukes fisiologia veterinária. Rio de Janeiro: Guanabara Koogan, 1996. p.35.

VALCARENGHI, D. Avaliação toxicológica crônica do polímero quitosana ferro (III) solúvel. 2006. 87f. (Dissertação de Mestrado) Universidade do Vale do Itajaí, Itajaí, SC.

ZHANG, SX. Atlas de histologia. Rio de Janeiro: Guanabara Koogan, 2001. p.152-157. 